\title{
Heritability for egg size in the serpulid polychaete Hydroides elegans
}

\author{
Cecelia M. Miles ${ }^{1, *}$, Michael G. Hadfield ${ }^{2}$, Marta L. Wayne ${ }^{3}$ \\ ${ }^{1}$ Department of Ecology and Evolution, University of Chicago, 1101 E. 57 Street, Chicago, Illinois 60637, USA \\ ${ }^{2}$ Kewalo Marine Laboratory, University of Hawaii, 41 Ahui Street, Honolulu, Hawaii 96813, USA \\ ${ }^{3}$ Department of Zoology, University of Florida, Box 118525, Gainesville, Florida 32611, USA
}

\begin{abstract}
Many quantitative models on the evolution of divergent life histories in marine invertebrates have focused on egg size with little empirical support for the assumption that significant heritability for egg size is present. Narrow-sense heritability $\left(h^{2}\right)$ is the proportion of total phenotypic variance in egg size that is made up of additive genetic variance, and is a predictor of short-term response to selection. We estimated $h^{2}$ for the trait of egg size in the polychaete worm Hydroides elegans using artificial selection and by using a half-sibling breeding design. The cumulative realized heritability was calculated as 0.58 for egg size in a population of $H$. elegans in Pearl Harbor, Hawaii. Similarly, the half-sib breeding design gave an estimate for $h^{2}$ of 0.45 for the same population. This indicates that there is substantial potential for egg size to respond to varying selective pressures, at least in the direction of increase.
\end{abstract}

KEY WORDS: Hydroides elegans $\cdot$ Narrow-sense heritability $\cdot h^{2} \cdot$ Egg size $\cdot$ Life-history evolution Resale or republication not permitted without written consent of the publisher

\section{INTRODUCTION}

Egg size is widely considered to be one of the most important characteristics of the life histories of marine invertebrates (Jaeckle 1995, Levitan 2000, McEdward \& Miner 2003). One feature often associated with egg size is the presence or absence of an obligate feeding larval stage in the life history. It has been hypothesized that nonfeeding larvae evolved as a response to either direct or indirect selection for increased egg size (Hart 1996, McEdward 2000). Selection on egg size has been linked to developmental mode (Miles \& Clark 2002), larval development time (Sinervo \& McEdward 1988, Reitzel et al. 2005), larval form (Strathmann 2000), size at settlement (Reitzel et al. 2005), survivorship (Moran \& Emlet 2001), and fertilization success (Levitan 2000).

Egg size has also been the focus of a series of quantitative modeling efforts to analytically assess the patterns observed in marine invertebrate life histories. Beginning with Vance's (1973) fecundity-time model, numerous authors have examined trade-offs between egg size, fecundity, mortality, and their relationship with the evolution of different reproductive strategies (e.g. Roughgarden 1989, McEdward 1997, Levitan 2000). Another set of models examined fertilization kinetics, which can also pose selective pressures on egg size and thus developmental mode (Levitan 1993, Luttikhuizen et al. 2004). While the quantitative modeling efforts regarding evolution of life histories in marine invertebrates have become increasingly refined, there has been little research into the genetic architecture of the important trait of egg size in marine invertebrates.

The focus of these diverse efforts has been on egg size as a proxy for maternal investment, and it is generally presumed that larger eggs represent a larger per-offspring investment by the parent, especially in those groups with a feeding (planktotrophic) larval stage. The trade-off between the costs and benefits of per-offspring parental investment provide the basis for many current ideas regarding the evolution of divergent life histories. Egg size and egg energy are positively correlated across species among echinoderms (Jaeckle 1995, McEdward \& Morgan 2001), but within 
species the relationship is more complex and egg size becomes a less reliable predictor of egg energy (McEdward \& Morgan 2001). Energy content is positively correlated with egg size across species in caridean shrimp (Clarke 1993, Anger et al. 2002) and polychaete annelids (Pernet \& Jaeckle 2004).

We focus here on another central and largely uninvestigated assumption of these studies, specifically, the evolvability of egg size. In order for a trait to respond to natural selection it must have heritable variation, and that variability must have fitness consequences. Numerous studies have found that egg size typically exhibits phenotypic variability within species, and within clutches, across a wide range of taxa (Hadfield \& Strathmann 1996). Phenotypic variation $\left(V_{\mathrm{P}}\right)$ has several components, including the genetic $\left(V_{\mathrm{G}}\right)$, the environmental $\left(V_{\mathrm{E}}\right)$, and the interaction between them $\left(V_{\mathrm{G} \times \mathrm{E}}\right)$. Unless phenotypic variation represents some underlying genetic variation, then it is not heritable and is consequently unavailable to natural (or artificial) selection. $V_{\mathrm{G}}$ can be further partitioned; the component that accounts for the resemblance between offspring and parents in sexually reproducing organisms is called additive genetic variance $\left(V_{\mathrm{A}}\right)$; the proportion of $V_{\mathrm{P}}$ that is made up of $V_{\mathrm{A}}$ is a quantity called narrowsense heritability $\left(h^{2}=V_{\mathrm{A}} / V_{\mathrm{P}}\right)$. This value is a measure of the resemblance between parents and offspring after sexual recombination and, therefore, is a predictor of the short-term response to selection (Falconer \& Mackay 1996).

Among protostome invertebrates, the bulk of investigations into $h^{2}$ of egg size has been focused on the Arthropoda (reviewed by Fox \& Czesak 2000), especially the Insecta, a mostly terrestrial group that includes Diptera (flies and mosquitoes), Lepidoptera (moths and butterflies), and Coleoptera (beetles), among others. Many experiments have examined egg size in Drosophila melanogaster and demonstrated that there is a significant genetic component to variation for this trait (e.g. Azevedo et al. 1997, Schwarzkopf et al. 1999). Among lepidopterans, Fischer et al. (2004) estimated $h^{2}$ for egg size of ca. 0.4 in the butterfly Bicyclus anynana and Harvey (1983) reported $h^{2}$ for egg weight in the budworm Choristoneura fumiferana at 0.75. Fox (1993) estimated $h^{2}$ of egg size for the seed beetle Callosobruchus maculatus at 0.43 to 0.59 and 0.60 to 0.74 using 2 different designs. Czesak \& Fox (2003) calculated realized $h^{2}$ for egg size in the seed beetle Stator limbatus of 0.36 to 0.55 . Thus, there is abundant evidence of $V_{\mathrm{A}}$ for egg size in insects, and estimates of $h^{2}$ are generally moderate to large.

The only marine invertebrate to receive similar attention was the poecilogonous polychaete Streblospio benedicti, for which a reciprocal mating design to examine the genetic components of life-history traits gave a heritability estimate of 0.75 for egg diameter (Levin et al. 1991). With the exception of this one study on $S$. benedicti, a species with an unusual life history that includes producing both planktotrophic and lecithotrophic larvae, empirical support for theoretical assumptions concerning the heritability of egg size in marine invertebrates has not been examined.

The serpulid polychaete Hydroides elegans Haswell, 1883 is an excellent choice as a model organism for estimating $h^{2}$ for several reasons. It produces a large number of planktotrophic larvae that can be cultured in the laboratory with relative ease. The larvae will settle and metamorphose in culture in the presence of natural biofilms (Hadfield et al. 1994). The generation time is reasonably short, 16 to $28 \mathrm{~d}$ at optimal temperature, salinity, and food concentrations (Qiu \& Qian 1998). Both larvae and adult worms can be fed the chrysophyte alga Isochrysis galbana, which is easily cultured in the laboratory. H. elegans develops in the water column with no maternal care.

The objective of the present study was to obtain estimates of narrow-sense heritability for the trait of egg size in Hydroides elegans. We calculated $h^{2}$ using 3 different techniques. First, artificial selection on egg size was performed, and cumulative realized heritability was calculated according to the methods of Hill (1972). Next, we constructed a half-sib breeding design and used a nested ANOVA for analysis (Falconer \& Mackay 1996). Last, restricted maximumlikelihood analysis (Quercus Quantitative Genetics Software) was performed on the same data set.

\section{MATERIALS AND METHODS}

Collection and spawning. This project was completed at Kewalo Marine Laboratory, Honolulu, Hawaii, using protocols developed there by various workers. Wild worms were collected in November 2002 from Vexar screens suspended for 1 mo from a floating dock at Ford Island, Pearl Harbor, Hawaii. The sex of each worm was determined, and gametes were secured by agitation of the tube, resulting in release of gametes (Unabia \& Hadfield 1999). Gametes from 270 female worms were used to establish the initial laboratory population. At least 120 males were used, but the exact number of males was not determined.

We used a Nikon Coolpix 990 camera mounted on an Olympus compound light microscope to obtain digital images of eggs from each female immediately after their release. Mean egg diameter for each mother $(n=$ 10 eggs mother $^{-1}$ ) was obtained from these images using NIH Image software.

Larval cultures were established at densities of 5 to 10 larvae $\mathrm{ml}^{-1}$ in $1 \mathrm{l}$ plastic tripour beakers and raised in 
'pooled' cultures (4 or 5 mothers and 2 or 3 fathers beaker $^{-1}$ ) for Generations 1 to 3 . Each beaker had different and unique parents. Cultures were maintained at $25^{\circ} \mathrm{C}$, and fed $6 \times 10^{4}$ cells $\mathrm{ml}^{-1} \mathrm{~d}^{-1}$ of the chrysophyte alga Isochrysis galbana (Tahitian strain). I. galbana was cultured in the laboratory at room temperature and constant light, using f/2 media (Guillard 1975), and it was used as food for $H$. elegans during the exponential growth phase of the algal culture. All embryos were allowed to hatch in FSW (0.22 $\mu \mathrm{m}$ filtered seawater), and swimming larvae were counted approximately $12 \mathrm{~h}$ post-fertilization. At that time larval cultures were established at maximum densities of 10 larvae $\mathrm{ml}^{-1}$ and larvae were fed for the first time. Larvae were fed on Day 2 by adding the appropriate volume of algae to the larval culture beaker without changing water or beakers. On Days 3 and 4 larvae were fed, and both water and beakers were changed. Day 5 larvae were considered competent to settle and metamorphose.

Small transparent plastic chips $(2.5 \times 1.5 \times 0.08 \mathrm{~cm}$; K\&S Engineering, No. 1306) were placed in flowthrough seawater tables for $10 \mathrm{~d}$ in order to accumulate natural biofilm, which has been shown to induce settlement in Hydroides elegans (Hadfield et al. 1994). One biofilmed chip was placed in each well of a standard ice cube tray along with $15 \mathrm{ml}$ FSW, Isochrysis galbana $(6 \times$ $10^{4}$ cells ml-1), and 20 to 25 competent larvae.

Larvae and newly settled juveniles were fed daily at this food density without changing the water for $5 \mathrm{~d}$. This procedure allowed a wide window of opportunity for settlement and avoided inadvertent selection for early settling individuals. Ice trays were kept at room temperature $\left(\sim 24^{\circ} \mathrm{C}\right)$ in a Plexiglas rack on the bench top with ambient illumination. The position of trays within the rack was randomized daily. On Day 10 (post-fertilization), each chip was removed from the tray and all animals but 1 were removed. The survivor was determined by position on the chip, with that individual closest to the center selected to be the survivor. Thus, no inadvertent selection for early or late settling individuals, or for body size, took place during this process. At this point, the food level was increased 6 -fold $\left(36 \times 10^{4}\right.$ cells $\left.\mathrm{ml}^{-1}\right)$ and worms were fed during the daily FSW change until the animals had reached $6 \mathrm{wk}$ of age. At maturity (here defined as $6 \mathrm{wk}$ ), individual worms were placed in Petri dishes and spawned as before. Hydroides elegans is a protandrous hermaphrodite. Since we were measuring a maternal trait (egg size), we chose a generation time of $6 \mathrm{wk}$ in order to assure that 50 to $60 \%$ of the spawning population would be female. Three generations were raised under laboratory conditions, to minimize variance due to maternal effects. Then, 200 or more females were spawned to produce each of the 2 subsequent generations (217 in Generation 2 and 236 in Generation 3).
Within Generation 3 a subset of individual crosses was established to setup the breeding design experiment described below. Alongside the pooled cultures of mixed parentage described above, individual larval cultures consisting only of offspring from a unique mother crossed with a known father were raised under conditions identical to those described above.

Half-sib breeding design. A subset of the worms in Generation 3 was used as parents for the half-sib design experiment (Falconer \& Mackay 1996) that was analyzed in Generation 4. Ten males were arbitrarily selected, and their sperm was split between 2 females ( 3 females were fertilized from 1 male only). The result of this mating scheme is to produce offspring related in 2 different ways, that is, full-siblings (within females, or dams) and half-siblings (within males, or sires). The advantage of this design is to allow the partitioning of the phenotypic variance according to its source (the progeny of different males $\left[\sigma^{2}\right.$ SIRE $]$, the progeny of different females mated to the same male $\left[\sigma_{\text {DAM }}^{2}\right.$, and individual offspring of the same female $\left[\sigma^{2}\right.$ WITHIN $]$ ). The component of total variance attributable to sires is $1 / 4$ $V_{\mathrm{A} i}$ therefore, the most straightforward estimate of $h^{2}=$ $4 \sigma_{\text {SIRE }}^{2} / \sigma^{2}$ TOTAL (Falconer \& Mackay 1996).

Parents and offspring involved in this breeding design were raised in individual and not 'pooled' cultures, but otherwise all conditions were as described above. A fully nested random model ANOVA was then used to partition variance in egg diameter according to its source. Type III sums of squares were calculated using the general linear model of SAS Version 6.12 (PROC GLM, with RANDOM statement).

The variance component data were also used to calculate the additive genetic and residual coefficients of variation

and

$$
\mathrm{CV}_{\mathrm{A}}=100 \sqrt{V_{\mathrm{A}}} / \bar{X}
$$

$$
\mathrm{CV}_{\mathrm{R}}=100 \sqrt{V_{\mathrm{P}}-V_{\mathrm{A}}} / \bar{X}
$$

where $\bar{X}$ is the trait mean; as recommended by Houle (1992).

We also used restricted maximum likelihood (REML) to analyze these same data, using the nf3 program in Quercus of R. G. Shaw \& F. H. Shaw (University of Minnesota, USA; www.cbs.umn.edu/eeb/events/quercus.shtml). This program estimates the likelihood of observing the data given a set of parameters. Iterative methods are then used to find the set of parameters that maximize this likelihood. We used the program to perform REML on a 2-generation pedigree, with mean egg diameter of each Generation 4 'daughter' as the single character. The sources of total phenotypic variance were analyzed using the model $V_{\mathrm{P}}=V_{\mathrm{A}}+V_{\mathrm{D}}+$ $V_{\mathrm{E}}$. In this model the genetic variance mentioned above $\left(V_{\mathrm{G}}\right)$ is partitioned into 2 components, $V_{\mathrm{A}}$ (addi- 
tive) and $V_{\mathrm{D}}$ (dominance). Log-likelihood ratio tests were used to compare the fit of the model for significant differences $\left(\chi^{2}{ }_{1}\right)$ as successive variance components were constrained to zero. Technically, this violates the assumption of the likelihood ratio test because the null value of the parameter (i.e. variance $=$ 0) lies on the boundary of the feasible range. However, the test is believed to be conservative under these conditions (Pinheiro \& Bates 2000).

Linear regression of mid-offspring egg diameters onto maternal egg diameters was not used, because, while each daughter had an independent mother, they were not independent with respect to the father. Therefore, the assumption of independence necessary for the linear regression could not be met.

Selection. In Generation 7 the common laboratory population (Generation 6, 225 females total) was split into 6 lines. Three were established as selected lines, and 3 as control lines. Between 12 and 16 females were used to establish each line (12 females for Lines 1 and 2, 15 females for Lines 3 and 4, 16 females for Lines 5 and 6). In subsequent generations (Generations 8 to 10), 16 mothers were kept in each line. Within selected lines, the eggs from a specific mother were subsampled as described above. Measurements were made immediately, and eggs were fertilized only if the mean diameter of the eggs was $>1$ phenotypic standard deviation $\left(\sigma_{\mathrm{P}}\right)$ over the Generation 6 population mean. In subsequent generations, selection proceeded in the same manner, with mothers remaining in the line only if the mean diameter of their eggs exceeded $1 \sigma_{\mathrm{P}}$ over the mean of the selected mothers from the previous generation. If the mothers meeting this criterion happened to include multiple sisters, we retained no more than 2 sisters in a line within a generation. The same rule, that no more than 2 sisters remain in a line, was also followed for control lines. In control lines, every third or fourth female was fertilized without regard to the size of her eggs. Otherwise, eggs were handled exactly the same as for selected lines. All crosses were between 1 male and 1 female with no shared parentage. Males were chosen haphazardly with respect to the mean egg size of the clutch from which they came. Care was taken not to use siblings of either selected or control females as fathers. Larval culture and settlement proceeded as before. Selection continued for 4 generations ( 7 to 10). Egg diameter data for selected Line 1 in Generation 7 were lost due to a cor- rupted computer file and therefore were not included in calculations of realized heritability.

Generally, realized heritability is the change in mean trait value over each generation of selection (offspring mean-parental population mean) divided by the selection differential (trait mean for selected parents parental population mean). As selection was carried out in 1 direction only and the selected and control lines came from the same base population, the realized heritability was calculated according to the specific methods described by Hill (1972). Cumulative realized heritability was calculated as the difference between selected and control values at each generation $\left(X_{i}\right)$ times the cumulative selection differential for that generation $\left(S_{i}\right)$, summed over generations $\left(\Sigma X_{i} S_{i}\right)$. This quantity was divided by the sum over the square of the cumulative selection differential for each generation $\left(\Sigma S_{i}^{2}\right)$.

\section{RESULTS}

Mean egg diameter $(\mu \mathrm{m}, \pm \mathrm{SE})$ before selection was $44.78 \mu \mathrm{m}$ (0.15) and, after selection, the mean egg diameter of the selected lines was $49.23 \mu \mathrm{m}$ (0.35). Direct selection on egg diameter for 4 generations produced a shift of $4.45 \mu \mathrm{m}$ or $2.5 \sigma_{\mathrm{P}}$ from the common base population mean (Fig. 1). Fig. 2 illustrates the mean egg diameter $(\mu \mathrm{m}, \pm \mathrm{SE})$ in the base population for several generations before selection and among lines after selection began. Cumulative realized heritability was calculated using the method of Hill (1972) as 0.58. Bootstrapping based on re-sampling with

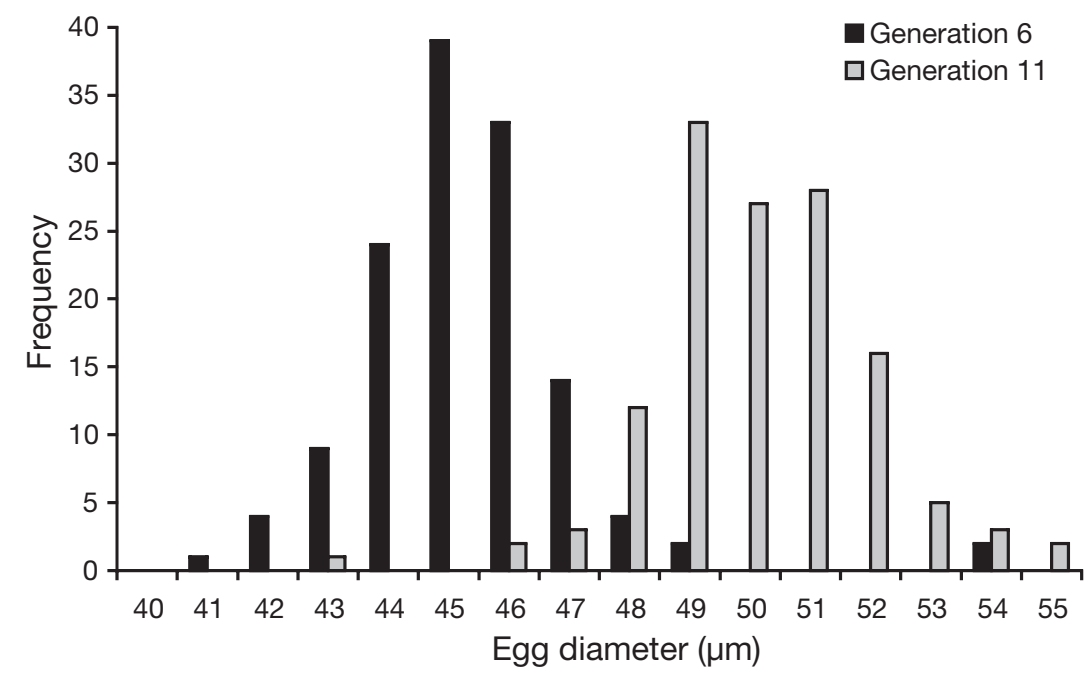

Fig. 1. Hydroides elegans. Response to direct selection on egg diameter for 4 generations. Selection began from a common base population in Generation 6 (10 eggs measured from 132 out of 266 total females) and lines were terminated in Generation 11 (10 eggs measured from all 212 females from 3 replicateselected lines) 


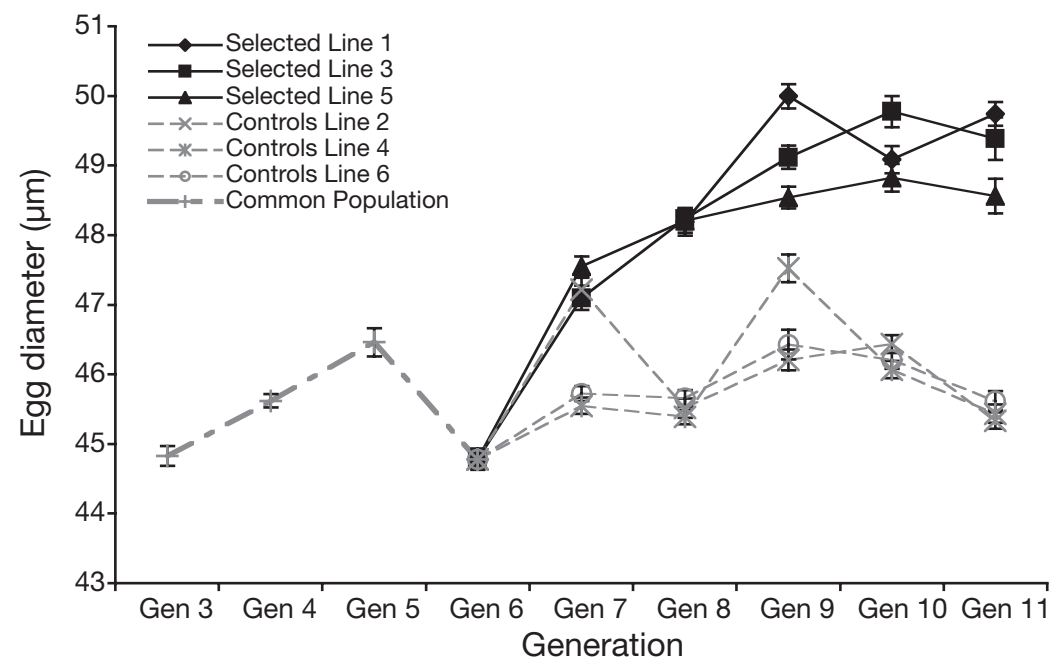

Fig. 2. Hydroides elegans. Mean egg diameter $( \pm \mathrm{SE})$ before and after direct selection for increased egg diameter in replicate-selected $(1,3,5)$ and control $(2$, $4,6)$ lines. SE for Generations 3 to 6 was based on total number of mothers measured per generation $\left(\mathrm{n}=10\right.$ eggs mother $\left.^{-1}\right)$ : Generation 3, $\mathrm{n}=227$; Generation $4, \mathrm{n}=310$; Generation 5, $\mathrm{n}=140$ of 277; Generation 6, $\mathrm{n}=132$ of 266. After selection SE shown was based on the mean of replicate lines (2 replicate-selected lines and 3 control lines in Generation 7 only, all other generations had 3 replicate lines for both selected and controls). Number of mothers measured after selection began ( $\mathrm{n}=10$ eggs mother $^{-1}$ ): Generation $7, \mathrm{n}=133$ selected and 216 control; Generation 8, n = 212 selected and 207 control; Generation 9, n = 240 selected and 227 control; Generation 10, $\mathrm{n}=211$ selected and 195 control; Generation 11, $\mathrm{n}=212$ selected and 222 control

replacement, and stratified by generation and line, was used to calculate $95 \%$ confidence intervals around this estimate. Confidence intervals based on 1000 replicates were 0.51 to 0.66 . We observed a positive response to selection through Generation 11 (calculated as the difference between replicate-selected and replicate-control lines within generations; Fig. 3). The overall difference in mean egg diameter between replicate-selected and control lines at Generation 11 was $3.77 \mu \mathrm{m}(49.23$ to $45.46 \mu \mathrm{m})$. This converts to a difference in mean egg volume of $1.72 \times 10^{-5} \mu \mathrm{l}(7.07 \times$ $10^{-5} \mu \mathrm{l}$ in selected lines and $5.35 \times 10^{-5} \mu \mathrm{l}$ in control lines at Generation 11).

Expected mean squares and variance components for the half-sib breeding design in Generation 4 are listed in Table 1. Narrow-sense heritability was calculated using the sire component of variance $(p=0.069)$ as $h^{2}=4 \sigma_{\text {SIRE }}^{2} / \sigma_{\text {TOTAL }}^{2}=0.45$. Confidence intervals were calculated based on the $F$-distribution, according to Knapp (1986), as recommended for small sample sizes (Hohls 1998). The $95 \%$ confidence intervals were large $(-0.36$ to 0.90$)$ and included zero. Confidence intervals for heritability estimates from breeding designs are very sensitive to the particular family design, to sample size, as well as other factors (Koots \& Gibson 1996, Markow \& Clarke 1997). The mean egg size of Generation 4 'daughters' used in the nested
ANOVA was $45.68 \mu \mathrm{m}( \pm 0.21 \mu \mathrm{m} \mathrm{SE})$, $\mathrm{CV}_{\mathrm{A}}=3.22$ and $\mathrm{CV}_{\mathrm{R}}=3.59$.

Results from the REML analysis on Generation 4 data were not significant. The full model $\left(V_{\mathrm{A}}, V_{\mathrm{D}}, V_{\mathrm{E}}\right.$ unconstrained) gave a negative estimate for $V_{\mathrm{D}}$. Since this is not biologically meaningful, $V_{D}$ was constrained to zero. This produced a result not significantly different than the unconstrained model $\left(\chi^{2}{ }_{1}=0.735 ; \mathrm{p}=0.45\right)$. The estimate of $h^{2}$ based on this model was $V_{\mathrm{A}} /\left(V_{\mathrm{A}}+V_{\mathrm{E}}\right)=0.38$. However, when $V_{\mathrm{A}}$ was constrained to zero the loglikelihood ratios were still not significantly different $\left(\chi^{2}{ }_{1}=2.519 ; \mathrm{p}=0.13\right)$.

\section{DISCUSSION}

There has been considerable interest in the evolution of life histories in marine invertebrates, and egg size has played a critical role in many of the quantitative modeling approaches that have been used to try to identify selection pressures and processes that influence the evolution of developmental mode in this group. In order for evolution to occur, some component of phenotypic variation in egg size must be additive genetic variation. Our objective was to determine if this central assumption of many models, that egg size can and does respond to selection, is reasonable by estimating $h^{2}$ for a marine inver-

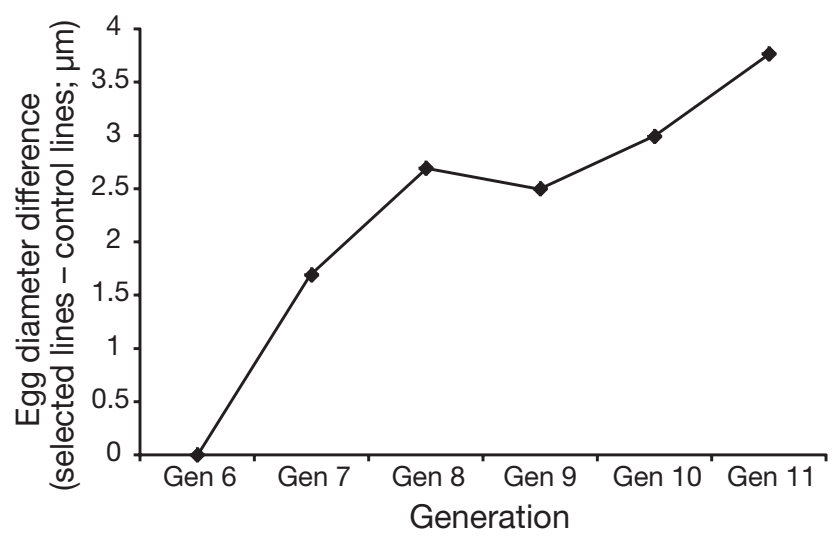

Fig. 3. Hydroides elegans. Cumulative response to artificial selection for increased egg diameter beginning at Generation 7 exhibited a positive trend through Generation 11. Response is graphed as the difference between the mean of replicateselected lines and the mean of replicate-control lines within generations. Generation 6 represents the common base population 
Table 1. Hydroides elegans. Fully nested ANOVA and variance component analysis of egg diameter (no. of observations 550, $s$ [no. of sites] $=10, d$ [no. of dams per site $]=2.1, k$ [mean no. of daughters per dam $]=2.6$ ). EMS: expected mean square; $V_{\mathrm{P}}$ : phenotypic variation

\begin{tabular}{|c|c|c|c|c|c|}
\hline Source & df & $\begin{array}{l}\text { EMS } \\
\left(\times 10^{-5}\right)\end{array}$ & $F$ & $\mathrm{p}$ & $\begin{array}{c}\text { Proportion } V_{\mathrm{P}} \\
\text { explained }\end{array}$ \\
\hline Sire & 9 & 4.149 & 2.65 & 0.069 & 11.13 \\
\hline Dam(Sire) & 11 & 1.575 & 0.769 & 0.667 & 0 \\
\hline Daughter(Dam(Sire)) & 34 & 2.047 & 8.16 & 0.0001 & 37.11 \\
\hline Error & 495 & 0.251 & - & - & 51.75 \\
\hline
\end{tabular}

tebrate with a wide geographic range, small egg, and obligate planktotrophic larvae.

We have shown that there is significant additive genetic variation for egg size in the Pearl Harbor population of Hydroides elegans using 2 different analytical techniques. The response of $2.5 \sigma_{\mathrm{P}}$ to direct selection on egg size indicates that there is substantial potential for egg size to respond to varying selective pressures, at least in the direction of an increase. The estimate of 0.58 for realized heritability for the trait of egg size in this population is strongly supported. In contrast, the estimate of $0.45 h^{2}$ based on the half-sib breeding design has very wide confidence intervals that include zero such that, without the selection work on the same population, the conclusion of non-zero heritability for this trait would be questionable. Calculating confidence intervals around heritability estimates is problematic, and the underlying nature of these problems is not well understood (Koots \& Gibson 1996). The estimate of the sire component of variance in our analysis is biologically relevant, explaining $>11 \%$ of the total variation on egg size, and statistically significant at $\alpha=0.07(p=0.069$; Table 1$)$, and therefore may be used to estimate $h^{2}$. Interestingly, the estimate of $h^{2}$ obtained from the general linear model is contained within the confidence limits of the estimate of realized heritability. However, the REML estimate from the same half-sibling experiment was not significantly different from zero. Retrospective tests of power $(80 \%)$ revealed that with a sample size as small as 12 sires these findings would have reached the threshold of $\alpha=0.05$. While the estimate based on the half-sib design lacks the precision of the estimate based on the selection experiment, taken together they present a convincing argument that there is significant genetic variation for the trait of egg size in this population.

Of course, all estimates of heritability carry the constraint that they only apply to the population measured, under the specific environmental conditions of measurement, and therefore should not be extrapolated to other populations or conditions (Falconer \& Mackay 1996). Though comparisons and/or extrapolations are often made, they should be made with caution. In addition, like most heritability estimates, this study was conducted in a laboratory setting; laboratory environments may alter relative levels of genetic and environmental variation in comparison to natural environments (Service \& Rose 1985).

In a half-sib breeding design, offspring have one parent in common (usually the male parent, or sire) and the other parent (usually the female parent, or dam) is different. The degree of resemblance among half-sibs (the covariance of half-sibs) represents half the variance of the shared parent, or a quarter of the additive genetic variance (ignoring epistasis, Falconer \& Mackay 1996). One of the advantages of using the sire component for estimating heritability is that it does not include maternal or dominance effects. It is possible to use this breeding design to estimate these effects by examining the variance within dams $\left(\sigma_{\text {DAM }}^{2}\right)$, since it includes both maternal (common environment) and dominance effects, and comparing it to the estimate based on the sire component. However, since our estimate of $\sigma_{\text {DAM }}^{2}$ was not significant ( $p=0.667$ ), and the proportion of $V_{\mathrm{P}}$ explained by this estimate was essentially zero (Table 1), further extrapolation based on this estimate cannot provide useful information. Maternal effects are widely recognized as important components of $V_{\mathrm{P}}$ (Mousseau \& Fox 1998), although this is more common in mammals and other taxa that practice maternal care. Table 1 also shows that the within dams the component of variance $\left(\sigma_{\text {WITHIN }}^{2}\right)$ is highly significant $(p=0.0001)$. Variation among daughters within mothers is likely due to environmental effects, and the size of this term could have obscured our ability to detect $\sigma_{\text {DAM }}^{2}$ and estimate maternal effects.

Cumulative realized heritability is considered the most precise of the various methods for determining narrow-sense heritability (Hill 1971), and our estimate of 0.58 using this technique has narrow confidence intervals, indicating reasonable precision. The cumulative realized heritability estimate does include maternal effects, since it is based on response to selection, but passing 6 generations under laboratory conditions prior to the beginning of selection minimized the phenotypic expression of any maternal effects. The half-sib breeding design gave only a slightly lower estimate of $h^{2}(0.45)$ compared to the cumulative realized heritability (0.58). The fact that 2 estimates are similar suggests that maternal and dominance effects are not large in this population with respect to this trait.

Many authors have noted that traits more closely related to fitness (e.g. fecundity, survivorship) tend to 
have lower heritabilities than traits that are less tightly associated with fitness (e.g. morphometric or behavioral traits) (Roff \& Mousseau 1987, Houle 1992). This pattern was initially interpreted as support for the idea that selection should reduce genetic variation more rapidly in traits closely related to fitness than in traits less closely related to fitness (Roff \& Mousseau 1987). But, many exceptions can be found (e.g. Levin et al. 1991, Fox \& Csezak 2000), including this work. Price \& Schluter (1991) suggest that no simple predictive relationship exists between $V_{\mathrm{A}}$ and whether a trait is considered more or less closely associated with fitness. Houle (1992) pointed out that because $h^{2}$ is a ratio of $V_{\mathrm{A}}$ to $V_{\mathrm{P}}$, the magnitude of $V_{\mathrm{P}}$ greatly influences the outcome: low $h^{2}$ could be the result of low $V_{\mathrm{A}}$ or high $V_{\mathrm{P}}$. Therefore, heritability is a biased estimate of additive genetic variance and potentially a misleading indicator of the ability of a particular trait to respond to selection. Using coefficients of variation, that is, $V_{\mathrm{A}}$ standardized by the trait mean rather than $V_{\mathrm{P}}$, is recommended as a more useful approach. Our estimates of $\mathrm{CV}_{\mathrm{A}}$ and $\mathrm{CV}_{\mathrm{R}}$ give very similar values (3.22 and 3.59 , respectively), implying that nearly half of the total variation present is additive genetic. This is consistent with our estimate of $h^{2}$.

Using the traditional methods of estimating $h^{2}$, and also by calculating $\mathrm{CV}_{\mathrm{A}}$, we have found significant levels of additive genetic variance for the trait of egg size in the Pearl Harbor population of Hydroides elegans and confirmed a genetic basis for variation in this important life-history trait. Several hypotheses have been offered to explain the apparent paradox of finding substantial $V_{\mathrm{A}}$ for a life-history trait that is closely linked to fitness. One such hypothesis is the presence of microevolutionary trade-offs. Microevolutionary tradeoffs occur when a change in one trait that acts to increase fitness is linked to a change in another trait that decreases fitness (Stearns 1992). These relationships can act to constrain the simultaneous evolution of suites of fitness-related traits and thereby maintain additive genetic variance in a population. Artificial selection on egg size and examination of the correlated responses of other fitness-related traits is one way to elucidate this relationship. Further analysis of our artificial selection data may shed some light on the presence or absence of trade-offs and the maintenance of genetic variation for fitness-related traits in this population.

Acknowledgements. This research was supported in part by ONR Grant N00014-03-1-0078 to M.G.H. and a Sigma Xi GIAR to C.M.M. We thank S. Kelly for help with measuring egg diameters, and B. Bolker and T. Okuyama for advice and discussion. We also thank R. Shaw for help with QUERCUS. Comments from 2 anonymous reviewers greatly improved this manuscript.

\section{LITERATURE CITED}

Anger K, Moreira GS, Ismael D (2002) Comparative size, biomass, chemical composition $(\mathrm{C}, \mathrm{N}, \mathrm{H})$ and energy concentration of caridean shrimp eggs. Invertebr Reprod Dev 42: 83-93

Azevedo RBR, French V, Partridge L (1997) Life-history consequences of egg size in Drosophila melanogaster. Am Nat 150:250-282

Clarke A (1993) Egg size and egg composition in polar shrimps (Caridea: Decapoda). J Exp Mar Biol Ecol 168: 189-203

Czesak ME, Fox CW (2003) Evolutionary ecology of egg size and number in a seed beetle: genetic trade-off differs between environments. Evolution 57:1121-1132

Falconer DS, Mackay TFC (1996) Introduction to quantitative genetics. Prentice Hall, Harlow

Fischer K, Zwaan BJ, Brakefield PM (2004) Genetic and environmental sources of egg size variation in the butterfly Bicyclus anynana. Heredity 92:163-169

Fox CW (1993) Maternal and genetic influences on egg size and larval performance in a seed beetle (Callosobruchus maculatus): Multigenerational transmission of a maternal effect? Heredity 73:509-517

Fox CW, Czesak ME (2000) Evolutionary ecology of progeny size in arthropods. Ann Rev Entomol 45:341-369

Guillard RRL (1975) Culture of phytoplankton for feeding marine invertebrates. In: Smith WL, Chaney MH (eds) Culture of marine invertebrate animals. Plenum Publishing, New York, p 29-60

Hadfield MG, Strathmann MF (1996) Variability, flexibility, and plasticity in life histories of marine invertebrates. Oceanol Acta 19:323-334

Hadfield MG, Unabia CC, Smith CM, Michael TM (1994) Settlement preferences of the ubiquitous fouler Hydroides elegans. In: Thompson $\mathrm{M}$, Nagabhushanam $\mathrm{R}$, Sarojini R, Fingerman M (eds) Recent developments in biofouling control. Oxford and IBH Publishing, New Delhi, p 65-74

Hart M (1996) Evolutionary loss of larval feeding: development, form and function in a facultatively feeding larva, Brisaster latifrons. Evolution 50:174-187

Harvey GT (1983) Environmental and genetic effects on mean egg weight in spruce budworm (Lepidoptera: Tortricidae). Can Entomol 115:1109-1117

Hill WG (1971) Design and efficiency of selection experiments for estimating genetic parameters. Biometrics 27:293-311

Hill WG (1972) Estimation of realised heritabilities from selection experiments. II. Selection in one direction. Biometrics 28:767-780

Hohls T (1998) Reliability of confidence interval estimators under various nested design parental sample sizes. Biom J 40:85-98

Houle D (1992) Comparing evolvability and variability of quantitative traits. Genetics 130:195-204

Jaeckle WB (1995) Variation in egg size, energy content, and composition of invertebrate eggs: correlates to the mode of larval development. In: McEdward LR (ed) Ecology of marine invertebrate larvae. CRC Press, Boca Raton, p 49-77

Knapp SJ (1986) Confidence intervals for heritability for twofactor mating design single environment linear models. Theor Appl Genet 72:587-591

Koots KR, Gibson JP (1996) Realized sampling variances of estimates of genetic parameters and the difference between genetic and phenotypic correlations. Genetics 143: $1409-1416$ 
Levin LA, Zhu J, Creed E (1991) The genetic basis of life-history characters in a polychaete exhibiting planktotrophy and lecithotrophy. Evolution 45:380-397

Levitan DR (1993) The importance of sperm limitation to the evolution of egg size in marine invertebrates. Am Nat 141: 517-536

Levitan DR (2000) Optimal egg size in marine invertebrates: theory and phylogenetic analysis of the critical relationship between egg size and development time in echinoids. Am Nat 156:175-192

Luttikhuizen PC, Honkoop PJC, Drent J, van der Meer J (2004) A general solution for optimal egg size during fertilization, extended scope for intermediate optimal egg size and the introduction of Don Ottavio 'tango'. J Theor Biol 231:333-343

Markow TA, Clarke GA (1997) Meta-analysis of the heritability of developmental stability: a giant step backward. J Evol Biol 10:31-37

McEdward LR (1997) Reproductive strategies of marine benthic invertebrates revisited: facultative feeding by planktotrophic larvae. Am Nat 150:48-72

McEdward LR (2000) Adaptive evolution of larvae and life cycles. Cell Dev Biol 11:403-409

McEdward LR, Miner BG (2003) Fecundity-time models of reproductive strategies in marine benthic invertebrates: fitness differences under fluctuating environmental conditions. Mar Ecol Prog Ser 256:111-121

McEdward LR, Morgan KH (2001) Interspecific relationships between egg size and the level of parental investment per offspring in echinoderms. Biol Bull (Woods Hole) 200:33-50

Miles CM, Clark KB (2002) Comparison of biochemical composition and developmental mode in two populations of Costasiella [Opisthobranchia: Ascoglossa (=Sacoglossa)]. J Molluscan Stud 68:101-109

Moran AL, Emlet RB (2001) Offspring size and performance in variable environments: field studies on a marine snail. Ecology 82:1597-1612

Mousseau TA, Fox CW (1998) Maternal effects as adaptations. Oxford University Press, New York

Editorial responsibility: Don Levitan (Contributing Editor), Tallahassee, Florida, USA
Pernet B, Jaeckle WB (2004) Size and organic content of eggs of marine annelids, and the underestimation of egg energy content by dichromate oxidation. Biol Bull (Woods Hole) 207:67-71

Pinheiro J, Bates D (2000) Mixed-effects models in S and S-plus. Springer-Verlag, New York

Price T, Schluter D (1991) On the low heritability of lifehistory traits. Evolution 45:853-861

Qiu JW, Qian PY (1998) Combined effects of salinity and temperature on juvenile survival, growth and maturation in the polychaete Hydroides elegans. Mar Ecol Prog Ser 168: 127-134

Reitzel AM, Miles CM, Heyland A, Cowart JD, McEdward LR (2005) The contribution of the facultative feeding period to echinoid larval development and size at metamorphosis: a comparative approach. J Exp Mar Biol Ecol 317:189-201

Roff DA, Mousseau TA (1987) Quantitative genetics and fitness: lessons from Drosophila. Heredity 58:103-118

Roughgarden J (1989) The evolution of marine life cycles. In: Feldman FW (ed) Mathematical evolutionary theory. Princeton University Press, Princeton, p 270-330

Schwarzkopf L, Blows MW, Caley MJ (1999) Life-history consequences of divergent selection on egg size in Drosophila melanogaster. Am Nat 29:333-340

Service PM, Rose MR (1985) Genetic covariation among lifehistory components: the effects of novel environments. Evolution 39:943-945

Sinervo B, McEdward LR (1988) Developmental consequences of an evolutionary change in egg size: an experimental test. Evolution 42:885-899

Stearns SC (1992) The evolution of life histories. Oxford University Press, Oxford

Strathmann RR (2000) Functional design in the evolution of embryos and larvae. Cell Dev Biol 11:395-402

Unabia CRC, Hadfield MG (1999) Role of bacteria in larval settlement and metamorphosis of the polychaete Hydroides elegans. Mar Biol 133:55-64

Vance RR (1973) On reproductive strategies in marine benthic invertebrates. Am Nat 107:339-352

Submitted: December 30, 2005; Accepted: November 16, 2006 Proofs received from author(s): May 15, 2007 